\title{
Journal club: old tricks and fresh approaches
}

\section{Sinead Mary McGlacken-Byrne (D) , ${ }^{1}$ Mark O'Rahelly, ${ }^{1}$ Peter Cantillon, ${ }^{2}$ Nicholas M Allen ${ }^{1}$}

\begin{abstract}
${ }^{1}$ Department of Paediatrics, National University of Ireland Galway, Ireland

2Department of General Practice, National University of Ireland Galway, Ireland
\end{abstract}

\section{Correspondence to}

Nicholas M Allen, Department of Paediatrics, National University of Ireland Galway, Ireland, H91 YR71; nicholas.m.allen@ nuigalway.ie

SMM-B and MO are joint first authors.

Received 7 April 2019 Revised 19 July 2019 Accepted 5 August 2019 Published Online First 29 August 2019

\section{Check for updates}

(c) Author(s) (or their employer(s)) 2020. No commercial re-use. See rights and permissions. Published by BMJ.

To cite: McGlackenByrne SM, O'Rahelly M, Cantillon $\mathrm{P}$, et al. Arch Dis Child Educ Pract Ed 2020;105:236-241.

\begin{abstract}
Journal club is a long-standing pedagogy within clinical practice and education. While journal clubs throughout the world traditionally follow an established format, new approaches have emerged in recent times, including learnercentred and digital approaches. Key factors to journal club success include an awareness of the learning goals of the target audience, judicious article selection and emphasis on promoting the engagement of participant learners. This article reviews the role that journal club plays in modern clinical education and considers how to optimise its benefit for contemporary learners.
\end{abstract}

\section{INTRODUCTION History synopsis}

Journal clubs (JCs) remain a steadfast pedagogy within contemporary postgraduate clinical education. Since their inception, JCs have shared a common objective to create an environment where people with a shared professional interest can meet periodically to focus on interesting or topical medical research literature. The concept of a JC has been in existence for a lot longer than one may imagine. In the mid-1800s, Sir James Paget set up 'a kind of club...where we could sit and read the journals' at St Bartholomew's Hospital in London. $^{1-3}$ Sir William Osler led similar clubs during his time at McGill University in Montreal 'for the purchase and distribution of periodicals to which he could ill afford to subscribe'. ${ }^{4}$ In 1889 , Osler established the first formal 'journal club' at Johns Hopkins University in Baltimore. ${ }^{2}$ These early incarnations of JC may have represented rare opportunities for doctors to collaboratively discuss patient care in an era predating the widely available clinical guidelines, consensus statements, and web-based clinical decision resources that we have today.

\section{Why have a JC?}

Core intended goals and learning outcomes of modern-day JCs are outlined in box 1. While several of these may have pertained to JCs of the past, the functions of modern-day JCs have evolved to reflect our rapidly changing sociotechnical clinical landscapes, serving to enhance contemporary clinical education and communication networks. ${ }^{56}$ For example, the multitude of instantaneously available (online or otherwise) clinical information resources means that healthcare professionals no longer depend on JCs to inform best practice. Today, JCs are more often used as a forum for collective critical appraisal of published literature, as a method to enhance evidence-based learning, or as a way of keeping abreast of relevant published research. ${ }^{7}$ We consider the contemporary JC as a valuable, multidimensional educational intervention for clinicians and clinical educators alike.

\section{JC FORMAT}

\section{The classic format}

The traditional or classic JC format (figure 1) in its most stereotypical form usually occurs face-to-face. Peer-reviewed journal articles of interest are presented by a junior trainee, followed by discussions often led by the more senior members of the clinical hierarchy in attendance. This, or a similar process, is reproduced in many institutions all over the world. It confers distinct educational benefits, including improved critical thinking skills, increased knowledge of research design and enhanced research awareness. ${ }^{8} 9$ However, the stereotypical format described may have potential pitfalls (which could be, and indeed are, optimised in some institutions) as applied to a contemporary clinical environment. For example, a JC based around a didactic presentation runs the risk of attendees becoming passive listeners. ${ }^{6}$ JCs led and 


\section{Box 1 Proposed functions of contemporary journal} clubs

- Teaches critical appraisal of research design, biostatistics, and evidence quality. ${ }^{92829}$

> Promotes evidence-based practice. ${ }^{29} 30$

- Encourages lifelong learning. ${ }^{15}$

- Develops leadership and presentation skills. ${ }^{28}$

- Promotes mentorship and collaborative learning. ${ }^{12}$

- Disseminates new medical developments. ${ }^{12}$

- Broadens professional local and international networks. $^{31} 32$

- Inspires new research studies.

facilitated by senior clinicians may result in discussions dominated by those with more experienced viewpoints. Face-to-face meetings that adhere to rigid schedules do not suit healthcare professionals who work different shift patterns or who are geographically isolated. ${ }^{1011}$

\section{Modern approaches to a classic format}

JC has a lot to offer contemporary learners as a medical pedagogy. ${ }^{81213}$ Educational researchers view the potential of JC through the lens of educational theories that emphasise social learning, communities of practice and distributed leadership. ${ }^{14}$ The central premise of the JC format can be built on to reflect the principles of contemporary clinical education approaches, which value collaboration, participation and learner engagement (figure 1; box 2). ${ }^{14}{ }^{15}$ Although JC design can be approached in a multitude of ways depending on the educational, institutional or departmental context, we consider more recent complementary approaches below, which may promote deeper learning and a wider reach for participants.
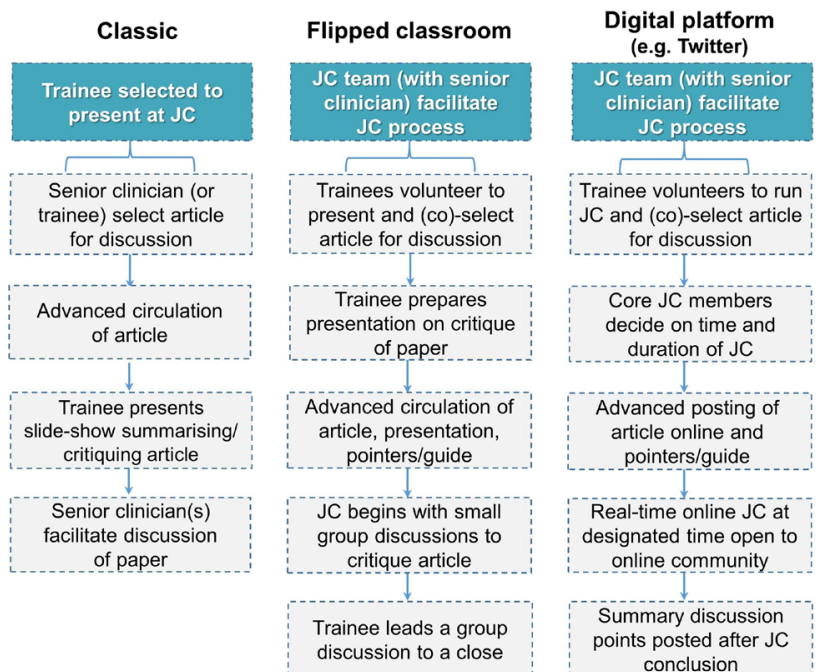

Figure 1 Examples of journal club (JC) formats. In practice, elements of the classic format can be incorporated into other formats, resulting in multiple potential hybrid approaches to JC that follow the guiding principles of JC design (box 2) and that address the key issues important to consider when setting up a new JC (box 3).

\section{Box 2 Guiding principles of journal club design}

- Guarantee both reputational safety and a challenging educational experience.

- Foster a safe learning environment, in which all participants can articulate areas of uncertainty, ask 'low level' questions, and share personal perspectives without fear of ridicule or censure.

- Balance learner/trainee autonomy against the learning needs of senior faculty.

- Allow learner/trainees the autonomy to develop their own learning experiences while also maintaining senior presence to facilitate and inform sessions.

- Customise educational design to the needs and requirements of the target group of learners.

- Exploit emerging communication technologies in order to enhance the reach, generalisability and effectiveness of the journal club experience.

Learner-centred approach

JCs are more effective if they have a leader, but this leader must be chosen carefully. ${ }^{8}$ It is a fine balance between selecting an expert facilitator who could potentially dominate the discussion and choosing a junior learner who may not have the requisite understanding of the material to engagingly facilitate the session. However, nominating a mentor to guide juniors in selecting their own article and leading on its discussion facilitates a learner-centred experience that promotes engagement and gives ownership of the process to the learners. ${ }^{915}$ This requires advanced planning, enthusiasm of both supervisors and trainees and possibly a forum for regular, informal discussion between the junior and mentor to ensure that the JC meetings do not become stale. ${ }^{1}$

'Flipped classroom' approach

A flipped classroom approach to JC involves circulating the article for discussion in advance, along with preparatory reading work. ${ }^{6}$ Ensuring pre-session engagement represents a specific challenge. Video or online interactive tutorials can facilitate this process. ${ }^{16}$ Distributing an appraisal tool along with the reading material may also help. For example, the Critical Appraisal Skills Programme (CASP) tools are freely available online and can aid JC attendees in the appraisal of randomised controlled trials as well as other relevant study designs (eg, case-control studies, cohort studies, qualitative research, etc). ${ }^{17}$

When successful, flipped classroom approaches translate to less time spent didactically presenting information and more time for collaborative discussion and questions. Often, this approach involves small group discussions, perhaps after a brief overview of the material at the outset. Small group discussions create an environment that encourages participants who otherwise may have been intimidated to step up and contribute. They also may help less knowledgeable 
attendees learn from the more experienced members of the group. ${ }^{18}$ Small group approaches also help to break up the ingrained physical layout of a room; chairs laid out in rows are instead placed in circles and trainees who previously congregated down the back of the room are now dispersed within it. These changes alone may break down hierarchical boundaries that impede learning.

\section{Digital platforms}

The advent of digital technology has revolutionised the way healthcare professionals communicate with one another. Online platforms and social media tools now make it possible to traverse national and international boundaries. ${ }^{19}$ Not surprisingly, a number of virtual JCs have emerged in recent years, starting first with online discussion boards, e-conferences and medical blogs. ${ }^{20}$ The virtual journal club then shifted to social media platforms, with the first interactive Twitter journal club established in 2011 and an eruption of Twitter journal clubs since that span multiple specialities. ${ }^{5} 21$ For example, the first paediatric Twitter journal club, @ADC_JC, was established in 2013 by Archives of Disease in Childhood and is still going strong today. Digital JCs are clearly popular and have the potential to spark discussion, disseminate best practice more widely and automatically result in an archived database of previous JC reviews. However, can the online JC learning experience emulate fully the socially constructed learning and knowledge gained from faceto-face interactions?

The most important consideration when developing any contemporary approach to JC is to ensure that its essential elements that have survived for decades are preserved while also harnessing digital connectivity and new educational approaches to our advantage, applicable locally or with wider reach. Some of the potential advantages and drawbacks to digital JC approaches are outlined in table 1 .

\section{SETTING UP A JOURNAL CLUB}

In words of one of the first JC proponents, Sir William Osler: 'The very first step towards success in any occupation is to become interested in it'. While the
Box 3 Optimising the journal club experience--

\section{key considerations}

- Identify your learners-What are their clinical and academic backgrounds?

- Ascertain the objective of your journal club (JC) What do your learners want to learn? Why?

- Selecting an article-What article types or concepts will spark discussion to achieve objective? Critical appraisal curriculum (see table 2)?

- Develop JC structure that best suits your learnersA classic, face-to-face JC? A virtual learning experience? Flipped classroom approach? Adapt hybrid model/aspects of each?

- Decide the practicalities

How often will your $\mathrm{JC}$ meet, and where and when? Access to resource material (presentations, literature, eg, deposited in Dropbox, accessible computer drive, email). Can information services/librarian assist? Appraisal tools (why, which, how will it help?).

- Decide how to promote JC engagement-What will your learners best respond to?

Free food? Mandatory attendance? Continuing medical education points/portfolio requirements?

A learning experience facilitated and led by trainees? Seniors willing to provide feedback (eg, presentation skills, JC delivery and evolution)?

- Develop JC resource, for example, available material from previous good JCs and good quality material related to critical appraisal education/techniques (eg, websites, articles, books, prior presentations).

- For digital platform JCs (eg, Twitter) consider: Ensuring a clear moderator for the session. ${ }^{11}$ Promoting the JC in advance (eg, websites, social media platforms, potential discussion points).

Register pre-decided hashtag \& use to keep discussion on track (eg, \#CochraneTrainees). ${ }^{33}$

Retweeting comments of newcomers to validate their contributions.

various modern approaches to JC have a lot to offer contemporary learners as medical pedagogies, several key considerations must be addressed when setting up a new journal club in order to optimise its delivery and effectiveness (box 3).

Table 1 Journal club on digital platforms

\begin{tabular}{ll}
\hline Advantages & Drawbacks \\
\hline Have the potential to disseminate best practice more widely & May favour those who are more comfortable with digital technology, for example, \\
Participants can join more than one journal club (JC), for example, a & potentially lead to less oversight from more expert senior member (unchecked inaccurate \\
digital, specialty-specific JC & posts) \\
Can spark national or international connections and collaborations & Limited (eg, 280-character Tweets) may not be enough to express critical viewpoint ${ }^{21}$ \\
Provides opportunities to invite international experts to participate & Real-time journal clubs may be too 'rapid fire' and difficult to follow \\
Potential participants who are geographically isolated can join an & Asynchronous discussion may lose momentum or pose a logistic problem (eg, \\
online community of practice at a place of their choosing & participation across time zones) \\
Allows flexible engagement outside of a strict schedule that may & Joining an online community as a newcomer may prove daunting for some \\
promote attendance among busy, for example, shift working, & Hierarchical boundaries may still exist, for example, senior clinicians may still contribute \\
learners & disproportionately to discussions \\
Provides an opportunity for JC engagement for those not usually & Potentially susceptible to undisclosed conflicts of interest or commercial influences \\
involved in academic medicine &
\end{tabular}


Table 2 Clinical Journal club material

\begin{tabular}{|c|c|c|}
\hline Material type & Examples & Comment \\
\hline \multirow[t]{2}{*}{ Original clinical research } & $\begin{array}{l}\text { Meta-analyses, systematic reviews, } \\
\text { randomised controlled trials, } \\
\text { observational studies }\end{array}$ & $\begin{array}{l}\text { Articles higher on "Evidence Pyramid", from high impact journals and } \\
\text { recent (eg, }<1 \text { year) have higher likelihood of changing practice. } \\
\text { Promote understanding of evidence hierarchy and critical appraisal } \\
\text { curriculum. } \\
\text { Discuss 'lower impact' similar study designs to compare. * }\end{array}$ \\
\hline & $\begin{array}{l}\text { Case reports/series, N-of-1 trials, } \\
\text { qualitative research }\end{array}$ & $\begin{array}{l}\text { May also demonstrate important, new or emerging clinically useful } \\
\text { concepts (despite 'lower' position on "Evidence Pyramid"). }\end{array}$ \\
\hline $\begin{array}{l}\text { Basic or translational scientific } \\
\text { research }\end{array}$ & $\begin{array}{l}\text { Articles with upcoming potential to } \\
\text { influence clinical care }\end{array}$ & $\begin{array}{l}\text { Keep clinician informed of scientific advances. } \\
\text { May be more relevant in academic/research active departments. } \\
\text { For example, "Testable antiarrhythmic therapy for long-QT syndrome... } \\
\text { using a patient-specific cellular model. Eur Heart J 2018;39(16)". }\end{array}$ \\
\hline \multirow{3}{*}{$\begin{array}{l}\text { Topic updates or overview of } \\
\text { relevant clinical concept } \\
\text { (combine with evidence } \\
\text { appraisal) }\end{array}$} & $\begin{array}{l}\text { Evidence-based guidelines (peer } \\
\text { reviewed) }\end{array}$ & $\begin{array}{l}\text { Overview of predefined clinical condition; could provide consensus } \\
\text { recommendations. } \\
\text { Benefit all members of JC/other MDT members. }\end{array}$ \\
\hline & Narrative reviews (peer reviewed) & $\begin{array}{l}\text { A state of the art review may identify gaps in literature, ideas (opinion- } \\
\text { based guidance) for practice and research. }\end{array}$ \\
\hline & Conference summary & $\begin{array}{l}\text { Attendees of a conference present overview of 'what's new'/emerging, } \\
\text { hot topics; generating discussion for practice and research. }\end{array}$ \\
\hline Online 'informal' material & $\begin{array}{l}\text { Forums, blogs, social media platforms, } \\
\text { websites }\end{array}$ & $\begin{array}{l}\text { Compare practices or research design. } \\
\text { Raise awareness or discuss controversy for example, evidence base or } \\
\text { lack of, for certain practices. }\end{array}$ \\
\hline
\end{tabular}

Decide on focus of your JC. What material will suit learners? Consider other material periodically. Consider involving interdisciplinary professionals. *Consider a curriculum-based approach, as well as discussion of less well-designed studies, in order to highlight common possible pitfalls when interpreting data or conducting different types of research studies.

JC, journal club; MDT, multidisciplinary team members.

\section{Consider who your learners are}

Creating a JC from scratch represents an opportunity to design a JC that best suits its learners. A key starting point is carefully considering the individual and collective needs of the attendees, taking into account their career goals and varying clinical and academic experience and mapping learning outcomes accordingly. ${ }^{22}$ Hospitalbased JCs often focus on developing critical appraisal skills, enhancing evidence-based practice and understanding the hierarchy of evidence. Therefore, many JCs in turn reflect 'Evidence-Based Medicine' curricula. ${ }^{23}$ In choosing articles, generally those published in high impact journals that are recent, paradigm changing and have the potential to influence clinical practice make for the bulk of good JC discussion material.

Just as every clinical question, research question or discovery cannot be answered by studies outlined in the typical 'Evidence Pyramid' and critical appraisal thereof, JC material may vary depending on context or even week. JCs still help to keep teams and individuals up to speed with topical and important research themes and, for example, material may also include case descriptions, qualitative research, clinical practice guidelines and review articles of major importance (table 2). ${ }^{24}$ Attendees involved in academia and scientific research may also be interested in translational research approaches. Occasional reviews of recent conferences or discussions around the evidence base for alternative or even controversial approaches in medicine may also appeal to attendees. While attendees 'rotating through' general paediatrics and its subspecialties may find these former approaches most relevant, medical JCs also represent an excellent opportunity for interprofessional education and learning, and so can be attended by and tailored towards multidisciplinary professionals. ${ }^{25}$

\section{Encouraging attendance and engagement}

The first step in creating a sustainable, effective JC that engages a learner group is to identify a core team to assist with the design process. This team should consist of genuinely enthusiastic, engaged junior learners and senior clinicians who are willing to act as facilitators of the JC process. ${ }^{8}{ }^{14}$ This team can then consider the key ingredients relevant to the learning contexts of their JC group.

The optimal size of journal club has yet to be determined, though at least eight attendees has been suggested for JCs at departmental level. The optimal execution of larger (eg, hospital-wide critical appraisal rounds) may differ, for example, more or less formal boundaries, participant and attendee roles, depending on group size. ${ }^{22} 26$ Provision of food has been debated and has been associated with increased attendance. ${ }^{8}$ Mandatory attendance has also been suggested to promote attendance, as has using JC to fulfil continuing medical education or 'e-portfolio' requirements. However, being physically present does not equal engagement, ${ }^{8} 27$ and while these incentives are useful to consider, the 
emphasis should be placed on actively engaging the target audience so that they realise there is something of value to be learnt during the sessions.

\section{CONCLUSION}

JCs remain a potentially powerful pedagogy within postgraduate clinical education in an era of abundant and instantly available clinical information resources. A JC based on several guiding principles will help ensure that learners engage with and attend JC for the sake of learning. Key to JC success include:

- Considering who the learners are and what they wish to learn.

- Ensuring that learning is social, collaborative, and not hampered by hierarchical boundaries.

- Combining key elements of the classic JC format with new educational approaches to suit the needs of contemporary learners.

- Harnessing the advantages of digital connectivity.

\section{What this study adds}

\section{What is already known on this topic}

- Journal club is a long-established pedagogy within clinical education.

\section{What this article adds}

- New approaches and formats to group learning have emerged in recent years in response to the changing educational and workplace environments and cultures. Modern technology has allowed journal club to be adapted to continue to play an important role in contemporary clinical education for today's learners.

Contributors SMB and MOR acquired, analysed and interpreted data for this study (literature review), drafted the article, co-wrote the article and wrote and revised subsequent drafts of the article. PC contributed to the content of the article, critically reviewed the article for important intellectual content and edited the article. NA conceptualised the study, supervised the study, contributed to the article, critically reviewed the article for important intellectual content and edited the article.

Funding The authors have not declared a specific grant for this research from any funding agency in the public, commercial or not-for-profit sectors.

Competing interests None declared.

Patient consent for publication Not required.

Ethics approval Hospital ethics approval was not requested due to study design.

Provenance and peer review Not commissioned; externally peer reviewed.

ORCID iD

Sinead Mary McGlacken-Byrne http://orcid.org/0000-0002-4289-0852

\section{REFERENCES}

1 Topf JM, Sparks MA, Phelan PJ, et al. The evolution of the Journal Club: from Osler to Twitter. Am J Kidney Dis 2017;69:827-36.

2 Linzer M. The Journal Club and medical education: over one hundred years of unrecorded history. Postgrad Med J 1987;63:475-8.

3 Paget S. Memoirs and letters of Sir James Paget. London Longmans: Green and Co, 1901.
4 Cushing H. The life of Sir William Osler Oxford. Oxford University Press, 1926.

5 Reich ES. Researchers tweet technical talk. Nature 2011;474:431.

6 Bounds R, Boone S. The flipped Journal Club. West J Emerg Med 2018;19:23-7.

7 Dirschl DR, Tornetta, P, Bhandari M. Designing, conducting, and evaluating Journal clubs in orthopaedic surgery. Clin Orthop Relat Res 2003;413:146-57.

8 Deenadayalan Y, Grimmer-Somers K, Prior M, et al. How to run an effective Journal Club: a systematic review. J Eval Clin Pract 2008;14:898-911.

9 Honey CP, Baker JA. Exploring the impact of Journal clubs: a systematic review. Nurse Educ Today 2011;31:825-31.

10 Rogers R, Mattu A, WInters M, et al. Practical teaching in emergency medicine Oxford. UK: Wiley-Blackwell, 2012.

11 Lizarondo L, Kumar S, Grimmer-Somers K. Online Journal clubs: an innovative approach to achieving evidence-based practice. J Allied Health 2010;39:e17-22.

12 Gottlieb M, King A, Byyny R, et al. Journal Club in residency education: an evidence-based guide to best practices from the Council of emergency medicine residency directors. West $J$ Emerg Med 2018;19:746-55.

13 Judd S, Antaki F. Approach to presenting a clinical Journal Club. Gastroenterology 2014;146:1591-3.

14 Quinn EM, Cantillon P, Redmond HP, et al. Surgical Journal Club as a community of practice: a case study. J Surg Educ 2014;71:606-12.

15 Kattan JA, Apostolou A, Al-Samarrai T, et al. Beyond content: leadership development through a Journal Club. Am J Prev Med 2014;47(5 Suppl 3):S301-5.

16 Jensen JL, Holt EA, Sowards JB, et al. Investigating strategies for Pre-Class content learning in a flipped classroom. J Sci Educ Technol 2018;27:523-35.

17 CASP. Critical appraisal of systematic reviews. critical appraisal skills programme; 2018.

18 Vgotsky L,Cole M, John-Steiner V, Scribner S, et al, eds. Mind in society: the development of higher psychological processes. Cambridge, MA: Harvard University Press, 1978.

19 Lewis B, Rush D. Experience of developing Twitter-based communities of practice in higher education. Research in Learning Technology 2013;21.

20 Yang PR, Meals RA. How to establish an interactive eConference and eJournal Club. J Hand Surg Am 2014;39:129-33.

21 Thangasamy IA, Leveridge M, Davies BJ, et al. International urology Journal Club via Twitter: 12-month experience. Eur Urol 2014;66:112-7.

22 Harris J, Kearley K, Heneghan C, et al. Are Journal clubs effective in supporting evidence-based decision making? A systematic review. BEME guide No. 16. Med Teach 2011;33:923.

23 Mohr NM, Stoltze AJ, Harland KK, et al. An evidence-based medicine curriculum implemented in Journal Club improves resident performance on the Fresno test. J Emerg Med 2015;48:222-9.

24 Hartzell JD, Veerappan GR, Posley K, et al. Resident run Journal Club: a model based on the adult learning theory. Med Teach 2009;31:e156-61.

25 Plastow NA, Boyes C. Unidisciplinary continuing professional development in a multidisciplinary world: experiences from practice. Work Based Learning in Primary Care 2006;4:32244. 
26 Elwyn G, Greenhalgh T, Macfarlane F. Groups: a guide to small group work in healthcare, management, education and research. Oxford: Radcliffe Medical Press, 2001.

27 Lao WS, Puligandla P, Baird R. A pilot investigation of a pediatric surgery Journal Club. J Pediatr Surg 2014;49:811-4.

28 Aronson JK. Journal clubs: 2. why and how to run them and how to publish them. Evid Based Med 2017;22:232-4.

29 Oliphant R, Blackhall V, Moug S, et al. Early experience of a virtual Journal Club. Clin Teach 2015;12:389-93.

30 Herur A, Kolagi S, Ramadurg U, et al. Refining the Journal Club presentations of postgraduate students in seven clinical departments for better evidence-based practice. Ann Med Health Sci Res 2016;6:185-9.

31 Topf JM, Hiremath S, media S. Social media, medicine and the modern Journal Club. Int Rev Psychiatry 2015;27:14754.

32 Lin M, Sherbino J. Creating a virtual Journal Club: a community of practice using multiple social media strategies. $J$ Grad Med Educ 2015;7:481-2.

33 Chan TM, Thoma B, Radecki R, et al. Ten steps for setting up an online Journal Club. J Contin Educ Health Prof $2015 ; 35: 148-54$. 